\title{
Genetic Susceptibility to Dental Caries Differs between the Sexes: A Family-Based Study
}

\author{
John R. Shaffer ${ }^{a, b} \quad$ Xiaojing Wang ${ }^{b-d}$ Daniel W. McNeil ${ }^{b, e}$ Robert J. Weyant $^{b, f}$ \\ Richard Crout $^{\text {b,g }}$ Mary L. Marazita ${ }^{a-d, h}$ \\ ${ }^{a}$ Department of Human Genetics, Graduate School of Public Health, University of Pittsburgh, and benter for Oral \\ Health Research in Appalachia, University of Pittsburgh, Pittsburgh, Pa., and West Virginia University, Morgantown, \\ W.Va., 'Center for Craniofacial and Dental Genetics, School of Dental Medicine, University of Pittsburgh, \\ dDepartment of Oral Biology, School of Dental Medicine, University of Pittsburgh, Pittsburgh, Pa., e Department of \\ Psychology, West Virginia University, Department of Dental Practice and Rural Health, West Virginia University of \\ Dentistry, Morgantown, W.Va., f Department of Dental Public Health and Information Management, University of \\ Pittsburgh, School of Dental Medicine, Pittsburgh, Pa., ${ }^{9}$ Department of Periodontics, West Virginia University School \\ of Dentistry, Morgantown, W.Va., and h Clinical and Translational Science Institute, and Department of Psychiatry, \\ School of Medicine, University of Pittsburgh, Pittsburgh, Pa., USA
}

\section{Key Words}

Gene-by-environment interaction (GxE) - Tooth decay .

Sex differences - Oral health

\begin{abstract}
Many of the factors affecting susceptibility to dental caries are likely influenced by genetics. In fact, genetics accounts for up to $65 \%$ of inter-individual variation in dental caries experience. Sex differences in dental caries experience have been widely reported, with females usually exhibiting a higher prevalence and severity of disease across all ages. The cause for this sex bias is currently uncertain, although it may be partly due to the differential effects of genetic factors between the sexes: gene-by-sex interactions. In this family based study ( $\mathrm{N}=2,663 ; 740$ families; ages 1-93 years), we assessed dental caries via intra-oral examination and generated six indices of caries experience (DMFS, $\mathrm{dfs}$, and indices of both pit-and-fissure surface caries and smooth surface
\end{abstract}

\section{KARGER 125\%}

(c) 2015 S. Karger AG, Basel

0008-6568/15/0492-0133\$39.50/0

E-Mail karger@karger.com

www.karger.com/cre caries in both primary and permanent dentitions). We used likelihood-based methods to model the variance in caries experience conditional on the expected genetic sharing among relatives in our sample. This modeling framework allowed us to test two lines of evidence for gene-by-sex interactions: (1) whether the magnitude of the cumulative effect of genes differs between the sexes, and (2) whether different genes are involved. We observed significant evidence of gene-by-sex interactions for caries experience in both the primary and permanent dentitions. In the primary dentition, the magnitude of the effect of genes was greater in males than females. In the permanent dentition, different genes may play important roles in each of the sexes. Overall, this study provides the first direct evidence that sex differences in dental caries experiences may be explained, in part, by gene-by-sex interactions.

(c) 2015 S. Karger AG, Basel 


\section{Introduction}

Dental caries is the process of enamel or dentin demineralization caused by acid produced by cariogenic oral bacteria. This process is opposed by the natural function of saliva to remineralize dental tissue by supplying calcium and phosphate ions that incorporate into the crystalline structure of tooth enamel [Lukacs and Largaespada, 2006; ten Cate et al., 2008]. Caries progression occurs as a result of an imbalance in the processes of demineralization and re-mineralization, eventually leading to cavitations [Featherstone, 2008]. Many factors can affect the processes of demineralization and remineralization including bacterial flora, dietary and oral hygiene behaviors, saliva composition, flow rate, and $\mathrm{pH}$ buffering capacity, positional and morphological features of the teeth, fluoride exposures, and socioeconomic factors including access to oral health care [Martinez-Mier and Zandona, 2013]. Host genetics may influence many of these factors leading to inter-individual variation in susceptibility to caries. Indeed, previous studies have shown that dental caries is highly heritable, with $20-65 \%$ of variation attributable to genetics [Boraas et al., 1988; Bretz et al., 2005a; Bretz et al., 2006; Bretz et al., 2005b; Shaffer et al., 2012a; Shaffer et al., 2012b; Shaffer et al., 2013b; Shaffer et al., 2012c; Shuler, 2001; Wang et al., 2010]. The current consensus is that the genetics of dental caries may be truly complex, affected not only by many genetic variants, but also by important interactions between genetic and nongenetic factors that may change over the life course.

In conjunction with the environmental and genetic risk factors listed above, sex also affects susceptibility to caries, with epidemiological surveys usually showing females at higher risk and having greater numbers of affected tooth surfaces compared to males [Lukacs and Largaespada, 2006; Martinez-Mier and Zandona, 2013]. The causes of sex differences in dental caries experience are not fully understood, although possible explanations include earlier tooth eruption (and thus longer exposure to cariogenic processes) in females, as well as sex differences in dietary and oral hygiene behaviors, utilization of oral health care, hormones/physiology, and characteristics of saliva [Lukacs and Largaespada, 2006; Martinez-Mier and Zandona, 2013]. The differential actions of genes in men and women have also been proposed [Ferraro and Vieira, 2010; Vieira et al., 2008]. Genetic variants related to tooth eruption, dietary preferences, physiology, saliva, or other unknown caries risk factors may have different effects in men versus women; such genetic effects are called gene-by-sex interactions.
While it is currently unknown whether gene-by-sex interactions are important for dental caries, recent findings from genetic studies have suggested that this may be the case. Sex chromosomes have been historically regarded as important for sexual dimorphism [Mank, 2009], and in a family based study, Vieira et al. identified a locus on the $\mathrm{X}$-chromosome showing suggestive linkage to dental caries $(p=5 E-5)$ [Vieira et al., 2008]. Similarly, a recent genome-wide association scan (GWAS) of dental caries by Zeng et al. implicated two highly homologous genes on opposite arms of the X-chromosome, BCOR $(\mathrm{p}=4 \mathrm{E}-7)$ and BCORL1 ( $\mathrm{p}=5 \mathrm{E}-6)$ [Zeng et al., 2013]. The same genetic variant in $B C O R L 1$ was also reported in a GWAS of novel caries phenotypes in the same sample ( $\mathrm{p}=3 \mathrm{E}-6)$ [Shaffer et al., 2013a]. Mutations in BCOR cause oculofaciocardiodental (OFCD) syndrome, a disorder presenting craniofacial and dental anomalies including cleft palate, radiculomegaly, delayed dentition, oligodontia, persistent primary teeth, and defective tooth enamel [Gorlin et al., 1996; $\mathrm{Ng}$ et al., 2004]. BCORL1 shows high sequence similarity to $B C O R$, although its function is unknown. Additionally, notable candidate genes reside on the $\mathrm{X}$-chromosome, such as AMELX, which codes amelogenin, the major protein component of the enamel matrix. Other genes on the X-chromosome, such as MST4 and FGF13, may also influence susceptibility to dental caries [Kuchler et al., 2014]. While X-inactivation in females is traditionally thought to balance the gene dosage between diploid females and haploid males for genes on the $\mathrm{X}$-chromosome, recent studies have shown that $15 \%$ of genes on the $\mathrm{X}$-chromosome escape inactivation to some degree, and another $10 \%$ show varying patterns of inactivation [Carrel and Willard, 2005]. Thus, $\mathrm{X}$-linked genes may be involved in gene-by-sex interactions via dosage effects.

While some genes related to sex differences, such as dental caries experience, may reside on the X-chromosome, the majority of gene-by-sex interactions likely involve autosomal loci [Wijchers et al., 2010]. Differential patterns of autosomal gene expression for males and females may occur for a number of reasons, including the response to estrogen or other sex hormones. Though others have speculated a possible role for gene-by-sex interactions on dental caries [Ferraro and Vieira, 2010; Vieira et al., 2008], no direct evidence for gene-by-sex interactions has yet been reported. In the present study we have used a family based approach to explore this question. Specifically, we have extended our previously published models of dental caries heritability [Shaffer et al., 2012c; Wang et al., 2010] to include the contribution 
Table 1. Biological relationships with the COHRA1 sample

\begin{tabular}{lr}
\hline Relative pairs & N \\
\hline Parent-offspring & 1,736 \\
Siblings & 676 \\
Grandparent-grandchild & 60 \\
Half-siblings & 322 \\
Avuncular (i.e., uncle-nephew) & 124 \\
First cousins & 98 \\
Other relatives & 35 \\
Total related pairs & 3,051 \\
Within kinship unrelated pairs (i.e., spouses, etc.) & 739 \\
Total pairs & 3,790 \\
\hline
\end{tabular}

of gene-by-sex interactions in explaining the observed correlation in dental caries experience among biological relatives.

\section{Methods}

The present study is a direct extension of the variance components models reported by [Wang et al., 2010] and [Shaffer et al., 2012c]. Although these previous studies reported the heritability of dental caries phenotypes (for the primary and permanent dentitions [Wang et al., 2010], and for pit and fissure vs. smooth tooth surfaces [Shaffer et al., 2012c]), in the current study we have extended the statistical models to include additional parameters quantifying the heritability in males and females separately, and allowing us to directly test for evidence of gene-by-sex interactions. Below, we briefly describe the methods of recruitment, data collection, and statistical analysis used in this study. The details of our extended statistical model are presented in the Appendix.

\section{Recruitment}

Household-based recruitment for the Center for Oral Health Research in Appalachia, cohort 1 (COHRA1) initiative was carried out in Allegheny, Washington, and McKean counties in Pennsylvania, and Webster and Nichols counties in West Virginia. Eligible households contained at least one biological parent-child pair, and all members of an eligible household were offered admission to the study regardless of legal or biological relationships or oral health status. Written informed consent was obtained for all adult participants; assent with written parental or guardian consent was obtained for all underage participants. All aspects of recruitment and data collection for the COHRA1 study were approved by the Institutional Review Boards of the University of Pittsburgh and West Virginia University. In total, 2,663 participants from 740 biological families of 1 to 20 members (with mean of 4.7 members) were enrolled. Table 1 shows the number of relative pairs (e.g., parentoffspring, siblings) available for analysis. All biological relationships were validated using genome-wide genetic marker data [Cornelis et al., 2010; Laurie et al., 2010] and standard relationship-testing methods [O'Connell and Weeks, 1998]. Additional details regarding the design of the COHRA1 study have been previously published [Polk et al., 2008; Shaffer et al., 2012c; Wang et al., 2010].

\section{Data Collection and Phenotype Definitions}

Dental caries was assessed via intra-oral examination by dentists or research dental hygienists calibrated at least annually across all sites. Interclass Correlation Coefficient (ICC) analysis was applied to quantify the consistency of caries assessments among and within the examiners. High correlation rates were observed for both inter (ICC >0.99) and intra-examiner reliability (ICC $0.86-$ 0.99) scores [Polk et al., 2008; Wendell et al., 2010]. Tooth surfaces were scored by visual inspection with a dental explorer using methods consistent with the National Center for Health Statistics Dental Examination Procedures Manual [2001] and recommended by the PhenX Toolkit [Hamilton et al., 2011] for comparability across genetic and epidemiological studies. Each tooth surface was classified as sound, precavitated decay, cavitated decay, filled/restored, missing due to decay, or missing due to reasons other than decay. Third molars were excluded from data collection. Edentulous participants were excluded from analysis.

DMFS index (i.e., the number of decayed, missing due to decay, or filled permanent tooth surfaces) was calculated for all participants with one or more permanent tooth present; $\mathrm{dfs}$ index (i.e., the number of decayed or filled primary tooth surfaces) was calculated for all participants with one or more primary teeth present. These caries indices were generated regardless of the participant's age. However, in general, younger children provided only the dfs index, older children provided both dfs and DMFS indices, and adolescents and adults provided DMFS index. Precavitated decay (i.e., 'white spot' lesions) was included in caries indices based on previous work showing that precavitated decay contributes to (rather than detracts from) the heritability of caries phenotypes [Wang et al., 2010]. The cause of each missing permanent tooth was provided by the participant as one of six possible reasons: trauma, orthodontia, decay, periodontitis, having never erupted, and other. Only missing teeth due to decay were included in DMFS indices.

Because caries risk factors may not uniformly impact surfaces across the dentition, partial DMFS and dfs indices were also calculated for two categories of tooth surfaces: pit and fissure (PF) surfaces, which included occlusal surfaces of molars and premolars, buccal surfaces of mandibular molars, and lingual surfaces of maxillary molars; and smooth (SM) surfaces, which included all other tooth surfaces. In total, six dental caries phenotypes were considered in this study: (1) DMFS, (2) PF DMFS, (3) SM DMFS, (4) dfs, (5) PF dfs, and (6) SM dfs. Data manipulations, descriptive statistics, and non-parametric (Wilcoxon) tests for sex differences were performed in the R statistical suite (R Foundation for Statistical Computing, Vienna, Austria).

\section{Statistical Approach}

The variance components method as implemented in SOLAR [Almasy and Blangero, 1998] was used to partition the phenotypic variance into environmental, heritable, and residual error components by conditioning on the biological relationships among the participants of the study. Likelihood methods were used to estimate model parameters, and statistical significance was determined by comparing full and constrained models using the likelihood ratio test. We extended the traditional heritability models 
Fig. 1. Heritability estimates in males and females, combined and separately, for dental caries indices in the primary (dfs) and permanent (DMFS) dentitions, and in pit and fissure (PF) and smooth (SM) tooth surfaces.

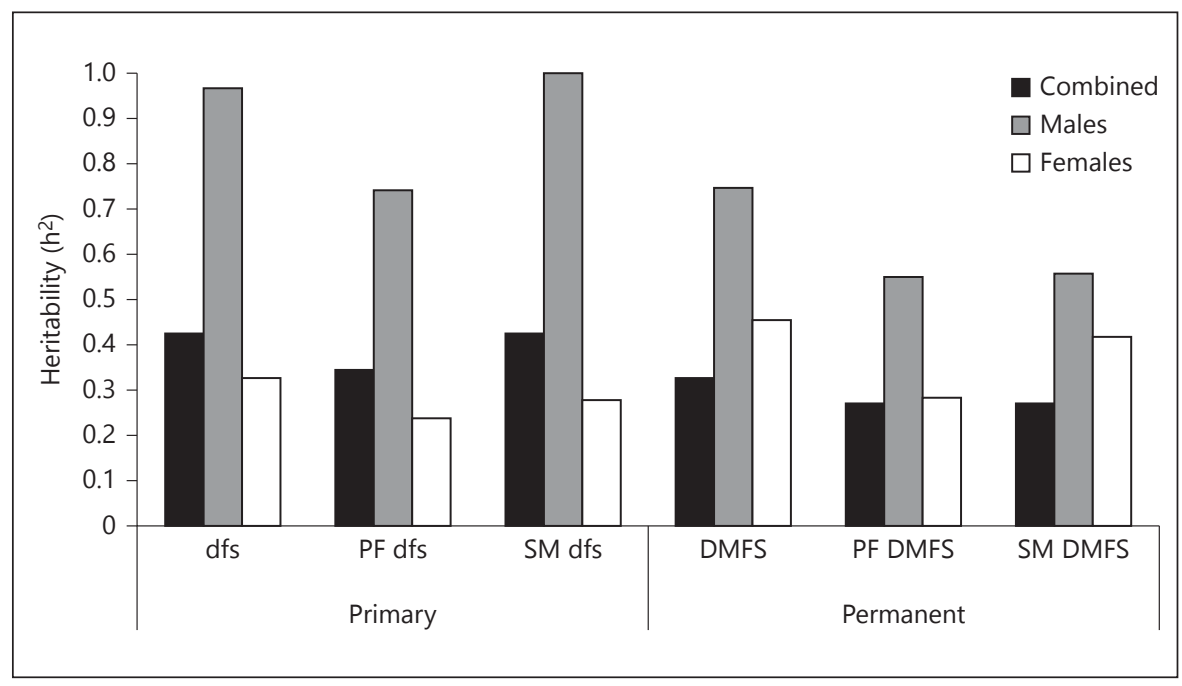

reported by [Wang et al., 2010] and [Shaffer et al., 2012c] by further partitioning the genetic variance, $\sigma_{\mathrm{G}}^{2}$, into separate sex-specific genetic variances, $\sigma_{\mathrm{GM}}^{2}$ and $\sigma_{\mathrm{GF}}^{2}$, and by including a new parameter, the male-female genetic correlation, $\rho_{\mathrm{G}}$, to describe the covariance between opposite-sex relative pairs. Models were adjusted for sex and age. See Appendix for model details.

The extended model allowed us to calculate sex-specific heritabilities (i.e., the proportion of phenotypic variance due to genetics in males and females) simultaneously. Moreover, the extended model provided a framework for testing two lines of evidence for gene-by-sex interactions: (1) whether the magnitude of the genetic variance differs between males and females (i.e., test $\sigma_{\mathrm{GM}}^{2} \neq \sigma_{\mathrm{GF}}^{2}$ ), and (2) whether the male-female genetic correlation differs from $100 \%$ (i.e., test $\rho_{\mathrm{G}} \neq 1.0$ ). A significant difference in the magnitude of the sex-specific genetic variances indicates that genes cumulatively have a larger role in caries experience in one sex compared to the other. A value for genetic correlation that is significantly less than 1.0 roughly indicates that different genes may be important for males than for females, and vice versa. Both of these statistical tests can provide evidence for the role of gene-by-sex interactions.

\section{Results}

Demographic characteristics of the sample and descriptive statistics of the dental caries phenotypes are shown in table 2. Among the COHRA1 participants having at least one primary tooth present, we did not observe sex differences in the proportion of primary tooth surfaces with caries (out of the total number of primary surfaces present; Wilcoxon $\mathrm{p}=0.33$ for smooth surfaces; $\mathrm{p}=$ 0.10 for pit and fissure surfaces). However, among COHRA1 participants having at least one permanent tooth present, the proportion of permanent tooth surfaces with caries (out of the total number of permanent sur-
Table 2. Demographic characteristics and summary statistics of dental caries phenotypes

\section{Summary statistics}

Sample size

Number of kinships

Size of kinships, mean (range)

Self-reported whites, \%

Females, \%

Age in years, mean \pm SD (range)

Primary dentition $(\mathrm{n}=1,058)$

$\mathrm{dfs}$, mean $\pm \mathrm{SD}$ (range)

$\mathrm{PF}$ dfs, mean $\pm \mathrm{SD}$ (range)

SM dfs, mean \pm SD (range)

Permanent dentition $(\mathrm{n}=1,937)$

DMFS, mean \pm SD (range)

PF DMFS, mean \pm SD (range)

SM DMFS, mean \pm SD (range)
2,663

740

$4.72(1-20)$

89.64

55.61

$19.83 \pm 15.29(1-93)$

$3.93 \pm 7.32(0-53)$

$1.85 \pm 3.09(0-16)$

$2.24 \pm 4.82(0-37)$

$14.34 \pm 18.76(0-122)$

$6.33 \pm 6.24(0-24)$

$8.18 \pm 13.82(0-98)$ faces present) was higher in females than in males ( $\mathrm{p}=$ 3.7E-5 for smooth surfaces; $\mathrm{p}=1.3 \mathrm{E}-6$ for pit and fissure surfaces). More detailed comparisons of caries rates between males and females within specific age groups have been previously reported for the COHRA1 sample [Shaffer et al., 2012c; Wang et al., 2010].

Figure 1 shows heritability estimates for males and females separately, and combined. The combined heritability estimates came from the classic heritability models as reported in [Wang et al., 2010] and [Shaffer et al., 2012c] where genetic effects were assumed to be identical in males and females. The sex-specific heritabilities were simultaneously estimated from our extended model. For all 
Table 3. Extended genetic model parameters and tests for gene-by-sex interactions

\begin{tabular}{|c|c|c|c|c|c|}
\hline \multirow[t]{2}{*}{ Trait } & \multirow[t]{2}{*}{$\sigma_{\mathrm{GM}}^{2}$} & \multirow[t]{2}{*}{$\sigma_{\mathrm{GF}}^{2}$} & \multirow[t]{2}{*}{$\rho_{\mathrm{G}}$} & \multicolumn{2}{|l|}{$\mathrm{p}$ values } \\
\hline & & & & $\sigma_{\mathrm{GM}}^{2}=\sigma_{\mathrm{GF}}^{2}$ & $\rho_{\mathrm{G}}=1.0$ \\
\hline \multicolumn{6}{|c|}{ Primary dentition $(\mathrm{n}=1,052)$} \\
\hline dfs & 59.3 & 15.0 & 0.40 & $0.0015^{\mathrm{a}}$ & $0.07^{\mathrm{b}}$ \\
\hline PF dfs & 8.1 & 2.0 & 0.56 & 0.0282 & 0.20 \\
\hline SM dfs & 25.4 & 5.8 & 0.34 & 0.0018 & 0.14 \\
\hline \multicolumn{6}{|c|}{ Permanent dentition $(\mathrm{n}=1,933)$} \\
\hline DMFS & 165.6 & 124.5 & 0.25 & 0.45 & 0.0038 \\
\hline PF DMFS & 12.5 & 7.8 & 0.50 & 0.35 & 0.09 \\
\hline SM DMFS & 74.0 & 67.6 & 0.15 & 0.87 & 0.0356 \\
\hline \multicolumn{6}{|c|}{$\begin{array}{l}\qquad \sigma_{\mathrm{GM}}^{2}=\text { Genetic variance in males; } \sigma_{\mathrm{GF}}^{2}=\text { genetic variance in females; } \rho_{\mathrm{G}}=\text { genetic correlation between males } \\
\text { and females; bold }=\mathrm{p} \text { values }<0.05 .{ }^{\text {a }} \text { Rejection of the null hypothesis implies that the magnitude of the genetic } \\
\text { effect differs between sexes. }{ }^{b} \text { Rejection of the null hypothesis implies that different genes contribute to the cu- } \\
\text { mulative genetic effect in the two sexes. }\end{array}$} \\
\hline
\end{tabular}

six caries phenotypes, males showed greater heritability than females and greater than both sexes combined. For primary dentition phenotypes, the combined heritability estimates were partway between those of the sexes, whereas for the permanent dentition phenotypes, the combined heritabilities were lower than for either of the sexes. Note that heritability is defined as the proportion of phenotype variability attributable to genetic causes. In other words, these values are ratios, and therefore dependent not only on the magnitude of the genetic contribution, but also on the magnitude of the total phenotype variance (which also includes the environmental contribution). Thus, strictly speaking, heritability estimates cannot be directly compared between the sexes to test for gene-by-sex interactions.

However, both sex-specific genetic variances and male-female genetic correlations can be used to test for gene-by-sex interactions. Table 3 shows the estimates of these parameters. For caries phenotypes in the primary dentition, genetic variances were significantly greater in males than in females ( $p=0.002$ to 0.028 ), but the genetic correlations were not different than 1.0 ( $p>0.05$ for all). The greater genetic variance in males suggests that in the primary dentition the magnitude of the genetic effect (i.e., the cumulative role of genes on caries susceptibility) differs between the sexes. However, the fact that genetic correlations were not different than 1.0 suggests that the same set of genes may be involved in both sexes. This is consistent with the sex-specific and combined heritability estimates (fig. 1). For caries phenotypes in the permanent dentition, the genetic variances were not significant-

Gene-by-Sex Interactions Affecting

Dental Caries ly different between males and females ( $\mathrm{p}>0.05$ for all). However, for DMFS and SM DMFS indices, the estimates of genetic correlation were both significantly less than 1.0 ( $\mathrm{p}=0.004$ and 0.038 , respectively), and for the PF DMFS index, the estimate of genetic correlation showed a similar trend (i.e., $\rho_{\mathrm{G}}=0.50$ ), although it was not quite statistically significant $(\mathrm{p}=0.09)$. These results suggest that the magnitudes of the genetic effects are similar between males and females, but that different genes or suites of genes may be involved in the different sexes. These results are also consistent with the observation that the sex-specific heritability estimates are both greater than the combined heritability estimate (fig. 1); the combined estimate reflects only the subset of genes contributing to caries experience in both sexes, and is expected to be comparatively lower if different genes are involved.

\section{Discussion}

In this study we presented the first direct evidence that gene-by-sex interactions may contribute to dental caries experience. We observed that in the primary dentition, the size of the role that genes play differed between males and females, whereas in the permanent dentition, different sets of genes may be involved. For both sexes, and across both dentitions, dental caries experience was moderately to highly heritable. Altogether, these results suggest that gene-by-sex interactions may be partly responsible for the observed sexual dimorphism in caries experience. Furthermore, these results suggest that fu- 
ture gene mapping studies seeking to identify the specific genes involved in dental caries may benefit by pursuing gene-by-sex interactions. Indeed, one of the dominant concerns borne by the growing GWAS literature is the problem of 'missing heritability', that is, the fact that specific genetic variants cumulatively account for only a fraction of the genetic variance observed in family studies. For dental caries, our results suggest that the 'missing heritability' may be partly due to gene-by-sex interactions.

Studying the etiology of dental caries experience poses a unique challenge in that the manifestation of the disease is difficult to capture in a single numeric phenotype. DMFS and dfs indices were analyzed and presented in this study, although these phenotypes have some limitations. For example, DMFS and dfs indices do not account for the number of teeth present in the mouth and therefore, for the number of teeth at-risk of developing caries (which varies among participants due to patterns of eruption and exfoliation in children, and tooth loss due to reasons other than caries in adults). Thus, a young participant who has few permanent teeth erupted, for example, may be expected to have a lower DMFS score than a participant with the full permanent dentition present. For this reason, we also analyzed six analogous caries phenotypes representing the proportion of affected surfaces (e.g., the DMFS index divided by the number of permanent teeth present, and so on for the other caries indices). The results (not shown) are very similar to the indices presented herein. In addition, age was included in the models presented herein to account for such effects. Another limitation is that DMFS and dfs indices exhibit a skewed distribution, which violates the normality assumption of the variance components model. Therefore, we also analyzed analogous caries phenotypes generated by performing the probit (i.e., inverse normal) transformation [Bliss, 1934] on the percentiles of the residuals of the caries indices. Analysis of the transformed caries indices, which were exactly normally distributed, yielded similar results, except for the transformed PF DMFS, which did not show evidence of gene-by-sex interaction ( $p=0.27$; results not shown). Taken together, these observations suggest that our conclusions are largely robust to the choice of phenotypes chosen for analysis. Moreover, noise in the phenotype measurement (such as that due to uncertainty regarding cause of missing teeth or reason for restoration) would bias our analyses toward the null hypotheses of no genetic variance in either sex, and no genetic correlation between the sexes. Given that we observed significant test results, our analysis frame- work was robust to potential noise due to measurement errors in the caries phenotypes.

In interpreting these results, it is important to note that gene-by-sex interactions represent a specific class of gene-by-environment interactions. Moreover, the sex of a study participant may be correlated with numerous other environmental exposures that are not taken into account in our analysis. Hence, the evidence of gene-by-sex interactions reported here includes the possible effects of other gene-by-environment interactions, where the environment is closely associated with sex. Therefore, this study does not offer insights into whether interactions are due to physiological differences, behavioral differences, differences in environmental exposures, or any other differences between the sexes. Nevertheless, these results mesh nicely with the position forwarded by Lukacs et al., that differences in physiology and saliva (which are likely influenced by genetics) may partly account for the observed sex differences [Lukacs and Largaespada, 2006].

This research was performed in an understudied, high-risk, rural population with poorer oral health than the US national average. Though caries rates are higher in this population, we speculate that the same risk factors that contribute to disease in our population also affect other populations, and our results are likely generalizable.

In conclusion, this study presents the first direct evidence that gene-by-sex interactions are involved in the dental caries experience. Therefore, we advocate that genetics should be considered, along with other potential causes, in efforts to understand the multi-factorial nature of the sex bias in dental caries. Indeed, insight gleamed from GWAS reinforces our hypothesis that dental caries is very complex, and that the next frontier in understanding disease may come from multidisciplinary approaches exploring the interactions among host genetics, epigenetics, environmental exposures, and microbial flora. Toward this end, more work is needed to understand the sex differences in dental caries, and ultimately to fully understand caries etiology, which may lead to improved interventions to prevent or oppose the disease process.

\section{Acknowledgments}

This work was supported by NIH and NIDCR grants R01DE014899 and U01-DE018903. The funders had no role in study design, data collection and analysis, decision to publish, or in the preparation of the manuscript. We would like to thank the investigators and staff who contributed to the COHRA1 study. Most of all, we would like to thank the COHRA1 study participants for their contribution toward understanding and improving the oral health of the Appalachian population. Author contributions: J.R.S. 
conceived the study, performed the data analysis, and wrote the manuscript; D.W.M., R.J.W., R.C., and M.L.M. conceived the COHRA1 initiative; J.R.S., X.W., D.W.M., R.J.W., R.C., and M.L.M. interpreted the results, and edited and approved the manuscript.

\section{Disclosure Statement}

All authors declare no conflicts of interest.

\section{Appendix}

The variance components modeling framework was used to estimate the additive genetic variance (and thereby estimate the 'narrow sense' heritability) of a trait by comparing phenotype measurements across all pairs of relatives and unrelated participants while conditioning on the expected genetic sharing (quantified by twice the kinship coefficient, $2 \varphi$ ) between the pairs. For example, parent-offspring pairs are expected to share $50 \%$ of their genome, sibling pairs share $50 \%$, half-sibling pairs share $25 \%$, uncle-nephew pairs share $25 \%$, grandparent-grandchild pairs share $25 \%$, cousin pairs share $12.5 \%$, and so on. The standard polygenic model used to estimate heritability takes the general form:

$$
\mathrm{p}_{\mathrm{i}}=\mu+\sum_{\mathrm{j}}^{\mathrm{n}} \beta_{\mathrm{j}} \mathrm{X}_{\mathrm{ji}}+\mathrm{g}_{\mathrm{i}}+\mathrm{e}_{\mathrm{i}}
$$

where $p_{i}$ is the phenotype for the ith participant, $\mu$ is the overall trait mean, $X_{i j}$ and $\beta_{j}$ are the values and regression coefficients, respectively, for the ith participant and jth covariate, $g_{i}$ is the additive genetic effect for the ith participant, and $\mathrm{e}_{\mathrm{i}}$ is the residual environmental effect for the ith participant. For this study we included sex and age as covariates: $p_{i}=\mu+\beta_{\text {sex }}$ sex $_{i}+\beta_{\text {age }}$ age $_{i}+g_{i}+e_{i}$. The corresponding variance model takes the form: $\sigma_{\mathrm{P}}^{2}=\sigma_{\mathrm{sex}}^{2}+\sigma_{\mathrm{age}}^{2}+\sigma_{\mathrm{G}}^{2}+$ $\sigma_{\mathrm{E}}^{2}$, where $\sigma_{\mathrm{P}}^{2}$ is the variance of the phenotype, $\sigma_{\mathrm{sex}}^{2}$ and $\sigma_{\mathrm{age}}^{2}$ are the components of the phenotypic variance due to covariates, $\sigma_{\mathrm{G}}^{2}$ is the genetic variance (i.e., the component of the phenotype variance attributable to the additive effects of all genes), and $\sigma_{\mathrm{E}}^{2}$ is the residual environmental variance (attributable to un-modeled and unmeasured environment factors). The genetic covariance between two relatives, $\mathrm{R}_{1}$ and $\mathrm{R}_{2}$ (e.g., parents and offspring, etc.) is $\operatorname{COV}\left(R_{1}, R_{2}\right)=2 \varphi \sigma_{G}^{2}$. This model assumes identical genetic effects in both males and females, and was used to estimate the combined heritability defined as follows:

$$
h^{2}=\frac{\sigma_{G}^{2}}{\sigma_{\mathrm{P}}^{2}-\sigma_{\text {sex }}^{2}-\sigma_{\text {age }}^{2}} .
$$

Maximum likelihood methods were used to estimate these model parameters simultaneously. The likelihood ratio test was used to determine statistical significance of parameters by comparing the likelihood of a model where the parameter is estimated to the constrained model where the parameter is set equal to its value under the null hypothesis. The test statistic follows the $\chi^{2}$ distribution for covariate parameters and a 50:50 mixed distribution of an $\chi^{2}$ and a point mass at zero for genetic parameters.

To test for the actions of gene-by-sex interactions we extended the standard variance components model, above, following the approach by Blangero and others [Blangero, 1993; Brown et al., 2004; Martin et al., 2002]. The extended variance model partitions the genetic and environmental variances into sex-specific components: $\sigma_{\mathrm{GM}}^{2}$ and $\sigma_{\mathrm{EM}}^{2}$ for males, and $\sigma_{\mathrm{GF}}^{2}$ and $\sigma_{\mathrm{EF}}^{2}$ for females. Under the extended model, the genetic covariance between same-sex relative pairs is $\operatorname{COV}\left(\mathrm{M}_{1}, \mathrm{M}_{2}\right)=2 \varphi \sigma_{\mathrm{GM}}^{2}$ for males and $\operatorname{COV}\left(\mathrm{F}_{1}, \mathrm{~F}_{2}\right)=$ $2 \varphi \sigma_{\mathrm{GF}}^{2}$ for females. In contrast, the genetic covariance between opposite-sex relative pairs is $\operatorname{COV}(\mathrm{M}, \mathrm{F})=2 \varphi \sigma_{\mathrm{GM}} \sigma_{\mathrm{GF}} \rho_{\mathrm{G}}$, where $\rho_{\mathrm{G}}$ is the male-female genetic correlation, which quantifies the degree to which the genetic influence on the trait is common to both sexes. In the absence of gene-by-sex interactions, the sex-specific genetic variances will be equivalent (i.e., $\sigma_{\mathrm{GM}}^{2}=\sigma_{\mathrm{GF}}^{2}$ ) and genetic correlation will equal $100 \%$ (i.e., $\rho_{G}=1.0$ ). On the other hand, in the presence of gene-by-sex interactions, the sex-specific genetic variances will differ (i.e., $\sigma_{\mathrm{GM}}^{2} \neq \sigma_{\mathrm{GF}}^{2}$, indicating the role of genes is larger in one sex compared to the other) and/or the genetic correlation will be less than $100 \%$ (i.e., $\rho_{\mathrm{G}}<1.0$, suggesting that different genes are involved in the two sexes). Gene-by-sex interactions were tested via likelihood ratio tests, which compared models where all parameters were simultaneously estimated to constrained models where the sex-specific genetic variances were forced to be equivalent and where the genetic correlation was forced to equal $100 \%$. Rejection of constrained models provides evidence of gene-by-sex interactions.

Of note, statistical power to detect heritability (i.e., $\mathrm{h}^{2}>0.0$ ) was high. However, power to detect gene-by-sex interactions was comparatively lower, due to the burden of estimating a greater number of model parameters, and the comparatively smaller number of informative relative pairs for estimating each parameter. Therefore, nonsignificant results should be cautiously interpreted as lack of evidence for gene-by-sex interactions, as opposed to evidence that interactions are nonexistent.

\section{References}

-Almasy L, Blangero J: Multipoint quantitative- Bretz WA, Corby PM, Hart TC, Costa S, Coelho trait linkage analysis in general pedigrees. Am J Hum Genet 1998;62:1198-1211.

Blangero J: Statistical genetic approaches to human adaptability. Hum Biol 1993;65:941-966.

Bliss CI: The method of probits. Science 1934;79: 38-39.

Boraas JC, Messer LB, Till MJ: A genetic contribution to dental caries, occlusion, and morphology as demonstrated by twins reared apart. J Dent Res 1988;67:1150-1155. MQ, Weyant RJ, Robinson M, Schork NJ: Dental caries and microbial acid production in twins. Caries Res 2005a;39:168-172.

Bretz WA, Corby PM, Melo MR, Coelho MQ, CostaSM, Robinson M, Schork NJ, Drewnowski A, Hart TC: Heritability estimates for dental caries and sucrose sweetness preference. Arch Oral Biol 2006;51:1156-1160.

Bretz WA, Corby PM, Schork NJ, Robinson MT, Coelho M, Costa S, Melo Filho MR, Weyant
RJ, Hart TC: Longitudinal analysis of heritability for dental caries traits. J Dent Res 2005b;84:1047-1051.

Brown LB, Streeten EA, Shuldiner AR, Almasy LA, Peyser PA, Mitchell BD: Assessment of sex-specific genetic and environmental effects on bone mineral density. Genet Epidemiol 2004;27:153-161.

-Carrel L, Willard HF: X-inactivation profile reveals extensive variability in $\mathrm{X}$-linked gene expression in females. Nature 2005;434:400-404.
Gene-by-Sex Interactions Affecting Dental Caries 
-Cornelis MC, Agrawal A, Cole JW, Hansel NN, Barnes KC, Beaty TH, Bennett SN, Bierut LJ, Boerwinkle E, Doheny KF, Feenstra B, Feingold E, Fornage M, Haiman CA, Harris EL, Hayes MG, Heit JA, Hu FB, Kang JH, Laurie CC, Ling H, Manolio TA, Marazita ML, Mathias RA, Mirel DB, Paschall J, Pasquale LR, Pugh EW, Rice JP, Udren J, van Dam RM, Wang X, Wiggs JL, Williams K, Yu K: The Gene, Environment Association Studies consortium (GENEVA): maximizing the knowledge obtained from GWAS by collaboration across studies of multiple conditions. Genet Epidemiol 2010;34:364-372.

Featherstone JD: Dental caries: a dynamic disease process. Aust Dent J 2008;53:286-291.

-Ferraro M, Vieira AR: Explaining gender differences in caries: a multifactorial approach to a multifactorial disease. Int J Dent 2010;2010: 649643.

Gorlin RJ, Marashi AH, Obwegeser HL: Oculofacio-cardio-dental (OFCD) syndrome. Am J Med Genet 1996;63:290-292.

-Hamilton CM, Strader LC, Pratt JG, Maiese D, Hendershot T, Kwok RK, Hammond JA, Huggins W, Jackman D, Pan H, Nettles DS, Beaty TH, Farrer LA, Kraft P, Marazita ML, Ordovas JM, Pato CN, Spitz MR, Wagener D, Williams M, Junkins HA, Harlan WR, Ramos EM, Haines J: The PhenX Toolkit: get the most from your measures. Am J Epidemiol 2011;174:253-260.

-Kuchler EC, Feng P, Deeley K, Fitzgerald CA, Meyer C, Gorbunov A, Bezamat M, Reis MF, Noel J, Kouzbari MZ, Granjeiro JM, Antunes LS, Antunes LA, de Abreu FV, Costa MC, Tannure PN, Seymen F, Koruyucu M, Patir A, Vieira AR: Fine mapping of locus Xq25.1-272 for a low caries experience phenotype. Arch Oral Biol 2014;59:479-486.

-Laurie CC, Doheny KF, Mirel DB, Pugh EW, Bierut LJ, Bhangale T, Boehm F, Caporaso NE, Cornelis MC, Edenberg HJ, Gabriel SB, Harris EL, Hu FB, Jacobs KB, Kraft P, Landi MT, Lumley T, Manolio TA, McHugh C, Painter I, Paschall J, Rice JP, Rice KM, Zheng $\mathrm{X}$, Weir BS: Quality control and quality assurance in genotypic data for genome-wide association studies. Genet Epidemiol 2010;34: 591-602.
Lukacs JR, Largaespada LL: Explaining sex differences in dental caries prevalence: saliva, hormones, and 'life-history' etiologies. Am J Hum Biol 2006; 18:540-555.

Mank JE: Sex chromosomes and the evolution of sexual dimorphism: lessons from the genome. Am Nat 2009;173:141-150.

Martin LJ, Mahaney MC, Almasy L, MacCluer JW, Blangero J, Jaquish CE, Comuzzie AG: Leptin's sexual dimorphism results from genotype by sex interactions mediated by testosterone. Obes Res 2002;10:14-21.

Martinez-Mier EA, Zandona AF: The impact of gender on caries prevalence and risk assessment. Dent Clin North Am 2013;57:301-315.

National Center for Health Statistics: National Health and Nutrition Examination Survey: Dental Examiners Procedures Manual, 2001.

- Ng D, Thakker N, Corcoran CM, Donnai D, Perveen $R$, Schneider A, Hadley DW, Tifft C, Zhang L, Wilkie AO, van der Smagt JJ, Gorlin RJ, Burgess SM, Bardwell VJ, Black GC, Biesecker LG: Oculofaciocardiodental and Lenz microphthalmia syndromes result from distinct classes of mutations in BCOR. Nat Genet 2004;36:411-416.

O'Connell JR, Weeks DE: Pedcheck: a program for identification of genotype incompatibilities in linkage analysis. Am J Hum Genet 1998;63:259-266.

Polk DE, Weyant RJ, Crout RJ, McNeil DW, Tarter RE, Thomas JG, Marazita ML: Study protocol of the Center for Oral Health Research in Appalachia (COHRA) etiology study. BMC Oral Health $2008 ; 8: 18$.

Shaffer JR, Feingold E, Wang X, Lee M, Tcuenco K, Weeks DE, Weyant RJ, Crout R, McNeil DW, Marazita ML: GWAS of dental caries patterns in the permanent dentition. J Dent Res 2013a;92:38-44.

Shaffer JR, Feingold E, Wang X, Tcuenco KT, Weeks DE, Desensi RS, Polk DE, Wendell S, Weyant RJ, Crout R, McNeil DW, Marazita ML: Heritable patterns of tooth decay in the permanent dentition: principal components and factor analyses. BMC Oral Health 2012a;12:7.
Shaffer JR, Feingold E, Wang X, Tcuenco KT, Weeks DE, DeSensi RS, Polk DE, Wendell S, Weyant RJ, Crout R, McNeil DW, Marazita ML: Heritable patterns of tooth decay in the permanent dentition: principal components and factor analyses. BMC Oral Health 2012b;12:7.

Shaffer JR, Feingold E, Wang X, Weeks DE, Weyant RJ, Crout R, McNeil DW, Marazita ML: Clustering tooth surfaces into biologically informative caries outcomes. J Dent Res 2013b;92:32-37.

Shaffer JR, Wang X, Desensi RS, Wendell S, Weyant RJ, Cuenco KT, Crout R, McNeil DW, Marazita ML: Genetic susceptibility to dental caries on pit and fissure and smooth surfaces. Caries Res 2012c;46:38-46.

-Shuler CF: Inherited risks for susceptibility to dental caries. J Dent Educ 2001;65:10381045.

ten Cate JM, Larsen MJ, Pearce EIF, Fejerskov O: Chemical interactions between the tooth and oral fluids; in Fejerskov O, Kidd E (eds): Dental caries: the disease and its clinical management. Wiley-Blackwell, 2008.

- Vieira AR, Marazita ML, Goldstein-McHenry T: Genome-wide scan finds suggestive caries loci. J Dent Res 2008;87:435-439.

-Wang X, Shaffer JR, Weyant RJ, Cuenco KT, DeSensi RS, Crout R, McNeil DW, Marazita ML: Genes and their effects on dental caries may differ between primary and permanent dentitions. Caries Res 2010;44:277-284.

Wendell S, Wang X, Brown M, Cooper ME, DeSensi RS, Weyant RJ, Crout R, McNeil DW, Marazita ML: Taste genes associated with dental caries. J Dent Res 2010;89:1198-1202.

-Wijchers PJ, Yandim C, Panousopoulou E, Ahmad M, Harker N, Saveliev A, Burgoyne PS, Festenstein R: Sexual dimorphism in mammalian autosomal gene regulation is determined not only by sry but by sex chromosome complement as well. Dev Cell 2010;19:477484.

Zeng Z, Shaffer JR, Wang X, Feingold E, Weeks DE, Lee M, Cuenco KT, Wendell SK, Weyant RJ, Crout R, McNeil DW, Marazita ML: Genome-wide association studies of pit-and-fissure- and smooth-surface caries in permanent dentition. J Dent Res 2013;92:432-437. 